\title{
THE 2005 AND 2010 AMAZONIAN DROUGHTS AS SEEN BY MODIS
}

\author{
Ranga B. Myneni \\ Boston University \\ ranga.myneni@gmail.com
}

\begin{abstract}
During this decade, the Amazon region in South America has suffered two severe droughts in the short span of five years - 2005 and 2010. The 2005 drought, dubbed a once-in-a-century drought, has been the focus and driver of many studies on the drought sensitivity of Amazon forests. These studies present a complex, and sometimes contradictory, picture of how these forests have responded to the 2005 drought. In particular, Saleska et al. (Science, 2007) reported excessive greening of the forests in response to the drought. But, this has now been proven by Samanta et al. (GRL, 2010) to be artifact of atmospheric-corruption of the satellite data analyzed by Saleska et al. (2007). In the first part of my talk, I will focus on the Saleska et al. and Samanta et al. studies. On the heels of the 2005 drought, came an even stronger drought in 2010, as indicated by record low river levels in the 109 years of bookkeeping. How have the forests responded to this record-breaking drought? Did they green-up or brown-down? I will address this in the second part of my talk. The objective of my talk will be to emphasize the care required in analysis and interpretation of satellite data.
\end{abstract}

